\title{
Modelling mitigation strategies for pandemic (H1N1) 2009
}

\author{
Marija Zivkovic Gojovic MSc, Beate Sander RN MEcDev, David Fisman MD MPH, \\ Murray D. Krahn MD MSc, Chris T. Bauch PhD
}

The full-text version of this article was published at www.cmaj.ca

\section{ABSTRACT}

Background: The 2009 influenza A (H1N1) pandemic has required decision-makers to act in the face of substantial uncertainties. Simulation models can be used to project the effectiveness of mitigation strategies, but the choice of the best scenario may change depending on model assumptions and uncertainties.

Methods: We developed a simulation model of a pandemic (H1N1) 2009 outbreak in a structured population using demographic data from a medium-sized city in Ontario and epidemiologic influenza pandemic data. We projected the attack rate under different combinations of vaccination, school closure and antiviral drug strategies (with corresponding "trigger" conditions). To assess the impact of epidemiologic and program uncertainty, we used "combinatorial uncertainty analysis." This permitted us to identify the general features of public health response programs that resulted in the lowest attack rates.

Results: Delays in vaccination of 30 days or more reduced the effectiveness of vaccination in lowering the attack rate. However, pre-existing immunity in $15 \%$ or more of the population kept the attack rates low, even if the whole population was not vaccinated or vaccination was delayed. School closure was effective in reducing the attack rate, especially if applied early in the outbreak, but this is not necessary if vaccine is available early or if pre-existing immunity is strong

Interpretation: Early action, especially rapid vaccine deployment, is disproportionately effective in reducing the attack rate. This finding is particularly important given the early appearance of pandemic (H1N1) 2009 in many schools in September 2009.

$\mathbf{J}$ urisdictions in the northern hemisphere are bracing for a "fall wave" of pandemic (H1N1) 2009..$^{1-3}$ Decision-makers face uncertainty, not just with respect to epidemiologic characteristics of the virus, ${ }^{4}$ but also program uncertainties related to feasibility, timeliness and effectiveness of mitigation strategies. ${ }^{5}$ Policy decisions must be made against this backdrop of uncertainty. However, the effectiveness of any mitigation strategy generally depends on the epidemiologic characteristics of the pathogen as well as the other mitigation strategies adopted. Mathematical models can project strategy effectiveness under hypothetical epidemiologic and program scenarios. ${ }^{6-12}$
In the case of pandemic influenza, models have been used to assess the effectiveness of school closure ${ }^{7}$ and optimal use of antiviral drug ${ }^{6,9,10}$ and vaccination strategies. ${ }^{8}$ However, model projections can be sensitive to input parameter values; thus, data uncertainty is an issue..$^{13}$ Uncertainty analysis can help address the impact of uncertainties on model predictions but is often underutilized..$^{13}$

In this article, we present a simulation model of pandemic influenza transmission and mitigation in a population. This model projects the overall attack rate (percentage of people infected) during an outbreak. We introduce a formal method of uncertainty analysis that has not previously been applied to pandemic influenza, and we use this method to assess the impact of epidemiologic and program uncertainties. The model is intended to address the following policy questions that have been raised during the 2009 influenza pandemic: What is the impact of delayed vaccine delivery on attack rates? Can attack rates be substantially reduced without closing schools? What is the impact of pre-existing immunity from spring and summer 2009? We addressed these questions using a simulation model that projects the impact of vaccination, school closure and antiviral drug treatment strategies on attack rates.

\section{Methods}

\section{Model}

\section{Population structure}

A model population of 10391 people was simulated based on demographic and employment data from 103 census tract units across London, Ontario, ${ }^{14}$ and data from the London District School Board. ${ }^{15}$ Individuals were assigned to one of the following age classes (age groups based on influenza susceptibility, dis-

From the Toronto Health Economics and Technology Assessment Collaborative (Gojovic, Sander, Krahn, Bauch); the Department of Mathematics and Statistics (Gojovic), York University; the Division of Clinical Decision-Making and Health Care Research (Sander, Krahn), University Health Network; the Ontario Agency for Health Protection and Promotion (Fisman); Research Institute of the Hospital for Sick Children (Fisman); Faculty of Pharmacy (Krahn), the Departments of Health Policy, Management and Evaluation (Sander, Krahn), Medicine (Krahn) and Epidemiology (Fisman), Dalla Lana School of Public Health, University of Toronto, Toronto, Ont.; and the Department of Mathematics and Statistics (Bauch), University of Guelph, Guelph, Ont.

Cite as CMAJ 2009. DOI:10.1503/cmaj.091641 
ease natural history and patterns of social interaction and behaviour): preschool (0-4 years), school children (5-9, 10-14, 15-19 years), adults (20-44, 45-64 years) and older adults ( $\geq 65$ years). Each individual was also allocated to a community, a household and, depending on age, a daycare, school or workplace, if employed (Table 1). Students were also assigned to a classroom on the basis of their age. The sizes of households, workplaces, daycares and schools were determined from demographic data. ${ }^{14,15}$ Every individual in the population was "scheduled" to spend a certain amount of time each day in each of these locations (Table 2), as determined by their infection status (Figure 1).

\section{Transmission and natural history}

Each newly infected individual entered a latent period that lasted 1.5 days on average. During this time, he or she was infected but not yet infectious to others. This was followed by a presymptomatic infectious period of 1 day, during which he or she felt well but could infect others. In $70 \%$ of individuals, this presymptomatic infectious period was followed by symptoms of influenza. The remaining individuals were asymptomatic for the duration of infection. ${ }^{3,4,10,16}$ On average, infected individuals stopped being infectious within 3 days if they were symptom- atic and 2.5 days if they were asymptomatic (Table 3).,3,410,16

Each simulated epidemic was seeded by infecting 10 randomly chosen individuals, and each simulation lasted 300 days. Each day, an infectious person could transmit infections through contacts at home, work, school, daycare or the community. The probability that an infected individual transmitted influenza to susceptible persons depended on the rate of potentially infectious contacts (which depended on the location), and the probability per contact of transmitting influenza. This per-contact transmission probability depended on the infectivity of the infectious individual, as well as susceptibility of the individual with whom they had contact (e.g., as modulated by vaccination status or age).,10,17-19 Additional assumptions were made about what percentage of symptomatic cases were diagnosed and the likelihood that infected individuals withdrew to home to recover. ${ }^{10}$ Details related to infectivity, susceptibility and likelihood of withdrawal are shown in Table 3. The impact of withdrawal on time spent in the various locations is presented in Table 2. Within homes and classrooms, all individuals encountered each another with equal probability. However, between classrooms and within workplaces and communities individuals had more contacts with others of a similar age. ${ }^{20}$ All of this

Table 1: Structure of the population included in the simulation model of pandemic influenza transmission

\begin{tabular}{|c|c|c|c|c|c|c|}
\hline Community & Population size & $\begin{array}{c}\text { No. of } \\
\text { households }\end{array}$ & $\begin{array}{c}\text { No. of } \\
\text { daycares }\end{array}$ & $\begin{array}{l}\text { No. of } \\
\text { elementary } \\
\text { schools }\end{array}$ & $\begin{array}{l}\text { No. of high } \\
\text { schools }\end{array}$ & $\begin{array}{c}\text { No. of } \\
\text { workplaces }\end{array}$ \\
\hline Community 1 & 4179 & 1365 & 5 & 2 & & 109 \\
\hline Community 2 & 2926 & 909 & 4 & 2 & & 108 \\
\hline Community 3 & 3286 & 1104 & 4 & 2 & & 108 \\
\hline Total & 10391 & 3378 & 13 & 6 & $1 *$ & 325 \\
\hline
\end{tabular}

*One high school was shared by all 3 communities.

Table 2: Calibrated contact rates, calibrated transmission probability per contact, and assumed time use patterns by location and status

\begin{tabular}{|c|c|c|c|c|c|c|}
\hline \multirow[b]{2}{*}{ Location } & \multirow[b]{2}{*}{$\begin{array}{c}\text { Calibrated } \\
\text { transmission } \\
\text { probability per } \\
\text { contact }\end{array}$} & \multirow[b]{2}{*}{$\begin{array}{l}\text { Calibrated no. of } \\
\text { contacts per hour }\end{array}$} & \multicolumn{4}{|c|}{ Time per day spent in location, ${ }^{*} \mathrm{~h}$} \\
\hline & & & Weekday & Weekend & $\begin{array}{l}\text { People who } \\
\text { withdraw } \\
\text { because they } \\
\text { are ill }\end{array}$ & $\begin{array}{l}\text { People who withdraw } \\
\text { to care for the ill or } \\
\text { because of school or } \\
\text { daycare closure }\end{array}$ \\
\hline $\begin{array}{l}\text { Household, adults } \\
\text { and children }\end{array}$ & 0.0095 & 2 & 4 & 8 & 12 & 10 \\
\hline \multicolumn{7}{|l|}{ Adults } \\
\hline Workplace & 0.0095 & 0.9 & 8 & 0 & 0 & 0 \\
\hline Community & 0.0095 & 0.0001 & 2 & 6 & 2 & 4 \\
\hline \multicolumn{7}{|l|}{ Children } \\
\hline Daycare classroom & 0.0095 & 3 & 7 & 0 & 0 & 0 \\
\hline School classroom & 0.0095 & 2 & 7 & 0 & 0 & 0 \\
\hline $\begin{array}{l}\text { School or daycare } \\
\text { outside classroom }\end{array}$ & 0.0095 & 0.9 & 1 & 0 & 0 & 0 \\
\hline Community & 0.0095 & 0.0002 & 2 & 6 & 2 & 4 \\
\hline
\end{tabular}

*The remaining 10 hours each day were spent away from potentially infectious contacts (e.g., sleeping) 
information was combined into a mathematical equation giving the total probability per day that a susceptible person would become infected (Appendix 1, available at www.cmaj.ca/cgi /content/full/cmaj.091641/DC1).

\section{Calibration}

We calibrated the contact rates in each location and the transmission probability per contact to ensure that the age-stratified attack rates in the model matched empirical age-stratified attack rates. ${ }^{3,421}$ The calibrated parameter values and the empirical data used for the calibration are presented in Table 3. The basic reproductive number $\left(R_{0}\right)$ is the average number of secondary infections produced by an infected person in an otherwise susceptible population. ${ }^{4,22-24}$ This important index determines the epidemic potential of an infectious disease. Simulations using the calibrated parameters gave an $R_{0}$ value of 1.8 (Appendix 1).

\section{Scenarios}

\section{Vaccination}

The 7 scenarios for pandemic vaccine coverage were (i) no vaccination; vaccination of (ii) $30 \%$ or (iii) $60 \%$ of the popu-

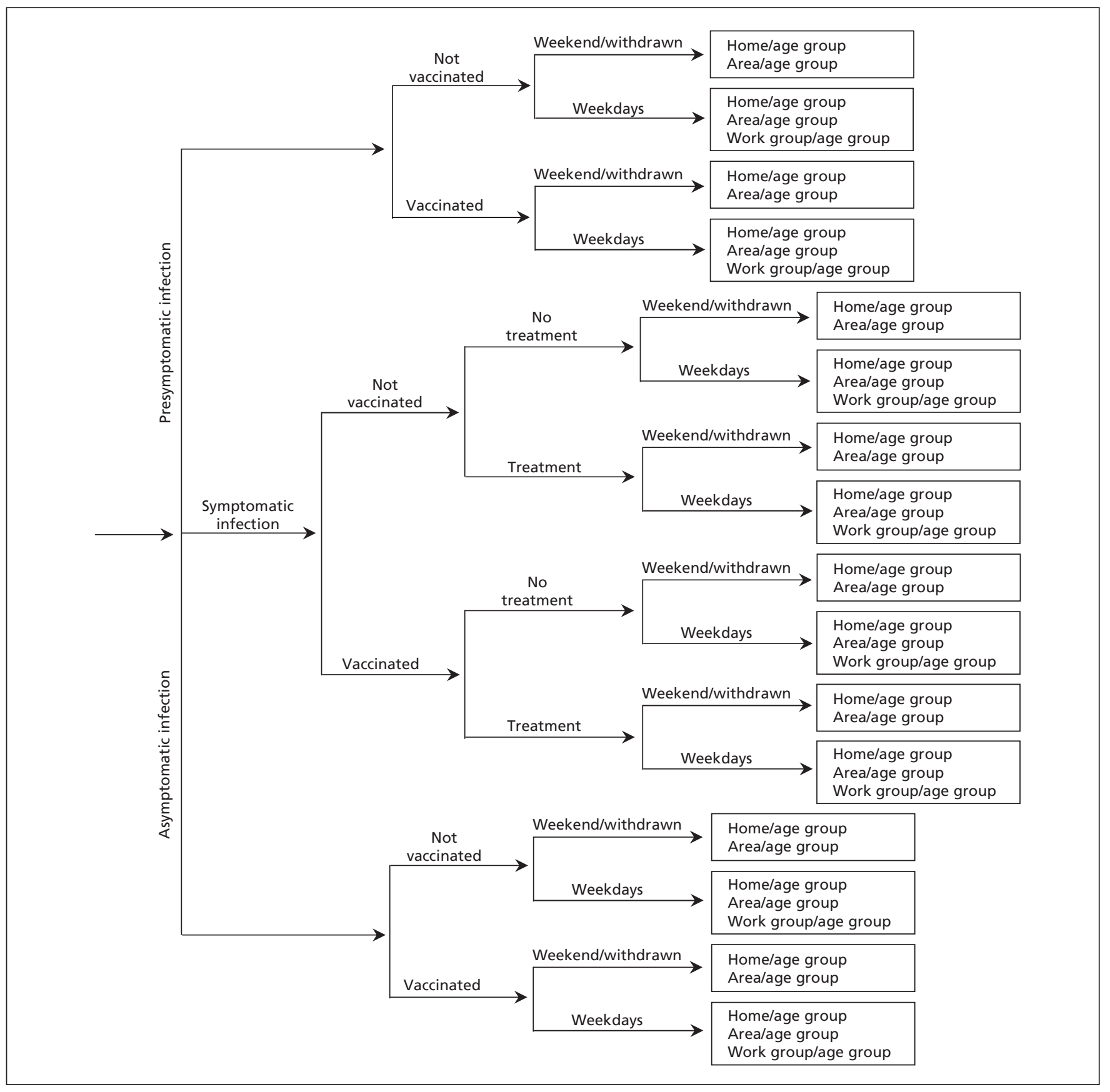

Figure 1: Decision tree showing the process by which an individual's daily time was allocated among home, work, school, daycare and community locations, as determined by infection status. 
lation before the outbreak; vaccination of (iv) $30 \%$ or (v) $60 \%$ of the population, starting 30 days after the outbreak began; and vaccination of (vi) $30 \%$ or (vii) $60 \%$ of the population, starting 60 days after the outbreak began. We assumed that it was possible to vaccinate one-third of the individuals in the vaccination group. Vaccination was available to those without

Table 3: Parameter values with sources

\begin{tabular}{|c|c|c|}
\hline Parameter description & Value & Source \\
\hline \multicolumn{3}{|l|}{ Duration of infection, * days } \\
\hline Symptomatic infection & Mean 3.0 , variance 1.0 & References $3,4,10,16$ \\
\hline Asymptomatic infection & Mean 2.5 , variance 1.0 & References $3,4,10,16$ \\
\hline Treated symptomatic infection & Mean 2.0, variance 1.0 & References $3,4,10,16$ \\
\hline Duration of latent period, ${ }^{*}$ days & Mean 1.5, variance 0.5 & References 3, 4, 10, 16 \\
\hline Age-stratified attack rate $\left(R_{0}=1.8\right), \%$ & & References 3, 4, 21 \\
\hline $0-4$ & $49 \%$ & \\
\hline $5-19$ & $55 \%$ & \\
\hline $20-64$ & $31 \%$ & \\
\hline$\geq 65$ & $27 \%$ & \\
\hline Proportion of infections that are symptomatic & 0.70 & Reference 4; assumption \\
\hline Proportion of symptomatic infections that are diagnosed & 0.90 & Reference 4; assumption \\
\hline $\begin{array}{l}\text { Probability that a symptomatic individual will withdraw } \\
\text { to home until recovery }\end{array}$ & & Reference 10; assumption \\
\hline Preschool children & $80 \%$ & \\
\hline School children & $75 \%$ & \\
\hline Adults & $65 \%$ & \\
\hline $\begin{array}{l}\text { Transmissibility of asymptomatic infection, relative to } \\
\text { those with symptomatic infections }\end{array}$ & 0.5 & \\
\hline $\begin{array}{l}\text { Probability that a school will close if a student is } \\
\text { symptomatic and diagnosed with the infection }\end{array}$ & $100 \%$ & Assumption \\
\hline $\begin{array}{l}\text { Probability that a daycare will close if a student is } \\
\text { symptomatic and diagnosed with the infection }\end{array}$ & $80 \%$ & Assumption \\
\hline $\begin{array}{l}\text { Probability that } 1 \text { parent with a child aged }<12 \text { years old } \\
\text { will stay home if the child's school is closed }\end{array}$ & $100 \%$ & Assumption \\
\hline Probability of adherence to antiviral drug therapy & $100 \%$ & Assumption \\
\hline $\begin{array}{l}\text { Susceptibility of children, relative to susceptibility of } \\
\text { adults }\end{array}$ & 2.06 & Reference 4 \\
\hline $\begin{array}{l}\text { Factor by which infectivity is reduced because of antiviral } \\
\text { therapy }\end{array}$ & 0.79 & References $10,17,18$ \\
\hline $\begin{array}{l}\text { Factor by which susceptibility of a vaccinated individual is } \\
\text { reduced, age, yr }\end{array}$ & & References 10,19 \\
\hline$<65$ & 0.70 & \\
\hline$\geq 65$ & 0.40 & \\
\hline $\begin{array}{l}\text { Factor by which infectiousness of a vaccinated individual } \\
\text { is reduced, age, yr }\end{array}$ & & References 10, 19 \\
\hline$<65$ & 0.80 & \\
\hline$\geq 65$ & 0.50 & \\
\hline $\begin{array}{l}\text { Age dependence for } 5 \% \text { and } 15 \% \text { pre-existing immunity; } \\
\text { age, yr }\end{array}$ & & References 3, 4, 21; assumption \\
\hline All ages & $5 \%, 15 \%$ & \\
\hline $0-4$ & $7.1 \%, 21.4 \%$ & \\
\hline $5-18$ & $8.6 \%, 25.7 \%$ & \\
\hline $19-64$ & $4.3 \%, 12.9 \%$ & \\
\hline$\geq 65$ & $3.4 \%, 10.7 \%$ & \\
\hline
\end{tabular}

*Sampled from Gaussian distribution 
a known recent history of influenza, and eligible individuals received vaccination at random.

\section{Antiviral drugs}

Antiviral drugs were used only for treatment of diagnosed infection, and enough doses were stockpiled to treat $25 \%$ of the population. ${ }^{25}$ All patients diagnosed with pandemic (H1N1) 2009 were given antiviral drugs for 5 days, and all individuals were assumed to adhere to treatment.

\section{School and daycare closure}

The 5 scenarios for closure of schools and daycares included both hypothetical rolling closures (where diagnosis of an infection in a school or daycare resulted in its closure for a period of time) and blanket school closures (where a diagnosed infection in 1 school or daycare resulted in a closure of every school and daycare in its community for a period of time). The scenarios were (i) no school closure; rolling closure for (ii) 7 or (iii) 14 calendar days; and blanket closure for (iv) 14 or (v) 300 calendar days. We assumed a 1-day delay between the identification of a case and school or daycare closure. Additional details are presented in Table 3.

\section{Triggers}

We explored 3 scenarios that would trigger closure of schools and daycares and release of antiviral stockpiles: (i) when the first infection is diagnosed in the population; and when the infection has been diagnosed in (ii) $1 \%$ or (iii) $5 \%$ of the population.

\section{Antiviral drug resistance}

We considered 2 scenarios: (i) the population was seeded with a strain that is not resistant to antiviral drugs; (ii) the population was seeded with a drug-resistant strain, such that the efficacy of drugs in reducing transmissibility was cut by $50 \%$.

\section{Pre-existing immunity}

The extent of pre-existing immunity in the Canadian population because of transmission in spring and summer 2009 is unknown. We explored 3 scenarios, in which (i) $0 \%$, (ii) $5 \%$ or (iii) $15 \%$ of the overall population had pre-existing immunity. Individuals with pre-existing immunity were assumed to be fully immune to infection. Pre-existing immunity varied according to age (Table 3 ).

\section{Combinatorial uncertainty analysis and baseline scenarios}

There were 630 possible combinations of the above scenarios. Rather than analyzing a small, preselected subset of these combinations and thereby excluding a large number of realistic possibilities, all 630 combinations were simulated 100 times each. The resulting attack rates were then stratified by scenarios of interest. For example, the top left entry of Table 4 shows the attack rates for "all vaccination scenarios combined" and "no school closure." There were 6 scenarios in which vaccination was used and 1 scenario in which school closure was not used. There was also 1 scenario for antiviral drug use, 3 scenarios for triggers, 2 scenarios for drug resistance and 3 scenarios for pre-existing immunity. This makes

Table 4: Pandemic influenza attack rates under various school closure and vaccination scenarios

\begin{tabular}{|c|c|c|c|}
\hline \multirow{3}{*}{$\begin{array}{l}\text { School or daycare closure } \\
\text { No closure }\end{array}$} & \multicolumn{3}{|c|}{ Attack rate, $* \%$, median ( $1 \mathrm{st}, 3$ rd quartile) } \\
\hline & All vaccination scenarios combined & \multicolumn{2}{|c|}{ No vaccination } \\
\hline & $4.0 \quad(1.3,10.4)$ & 21.7 & $(8.9,28.7)$ \\
\hline Rollingt 7-day closure & $1.6 \quad(0.7,3.8)$ & 4.5 & $(1.9,7.1)$ \\
\hline Rolling 14-day closure & $1.3 \quad(0.7,3.3)$ & 3.6 & $(1.5,5.3)$ \\
\hline Blanket‡ 14-day closure & $1.3 \quad(0.6,3.3)$ & 3.3 & $(1.0,5.5)$ \\
\hline Blanket 300-day closure & $1.3(0.5,3.1)$ & 3.1 & $(0.8,5.5)$ \\
\hline
\end{tabular}

Attack rate, * \%, median (1st, 3rd quartile)

\begin{tabular}{|c|c|c|c|c|}
\hline \multirow{3}{*}{$\begin{array}{l}\text { Vaccination status } \\
\text { No vaccination }\end{array}$} & \\
\hline & \multicolumn{2}{|c|}{ All school and daycare closure scenarios combined } & \multicolumn{2}{|c|}{ No school or daycare closure } \\
\hline & 3.4 & $(1.2,6.3)$ & 21.7 & $(8.9,28.7)$ \\
\hline \multicolumn{5}{|l|}{ Vaccinate $30 \%$ of the population } \\
\hline Before the outbreak & 0.9 & $(0.5,2.0)$ & 3.7 & $(1.0,7.0)$ \\
\hline Starting 30 days after outbreak begins & 2.2 & $(0.8,3.4)$ & 7.6 & $(2.1,10.7)$ \\
\hline Starting 60 days after outbreak begins & 3.2 & $(1.1,4.7)$ & 12.5 & $(1.1,18.1)$ \\
\hline \multicolumn{5}{|l|}{ Vaccinate $60 \%$ of the population } \\
\hline Before the outbreak & 0.4 & $(0.3,0.8)$ & 0.7 & $(0.3,1.0)$ \\
\hline Starting 30 days after outbreak begins & 1.4 & $(0.7,2.9)$ & 3.7 & $(1.3,4.8)$ \\
\hline Starting 60 days after outbreak begins & 3.0 & $(1.0,4.4)$ & 9.9 & $(2.9,14.3)$ \\
\hline
\end{tabular}

*All other possible combinations of antiviral drug use, triggers, drug resistance, and pre-existing immunity.

tDiagnosis of an infection in a school or daycare caused the location to be closed.

‡Diagnosis of an infection in a school or daycare caused every school and daycare in its community to be closed. 
108 possible scenario combinations in which vaccination was used but with no school closures.

Two specific "baseline scenarios" were also chosen to represent most the likely situations. The "no mitigation" baseline assumed 5\% pre-existing immunity, no antiviral resistance and no mitigation strategies. The "mitigation" baseline assumed 5\% pre-existing immunity, no antiviral resistance, antiviral treatment beginning with the first diagnosed case, no school closures and vaccination of $30 \%$ of the population starting 30 days after the outbreak began.

\section{Results}

Typical simulated epidemics of the 2 baseline scenarios are shown in Figure 2. The median epidemic peak under the "no mitigation" scenario was 47 cases (41 in the first quartile, 53 in the third quartile) and the median attack rate was $22.2 \%$. In comparison, the median epidemic peak under the mitigation scenario was 18 cases (13 in the first quartile, 24 in the third quartile) and the median attack rate was $6.2 \%$.

It is difficult to make generalizations from baseline scenarios because they require a very specific set of assumptions. We therefore used combinatorial uncertainty analysis to make more general conclusions under epidemiologic and program uncertainties. Despite variability in attack rate across scenarios because of the uncertainties embodied in the list of scenarios, general trends are apparent in multiple combinations of simulations (Table 4, Table 5, Table 6, Appendix 1), For example, closure of schools and daycares was effective in reducing the attack rate (e.g., in the no vaccination group: $4.5 \%$ with a rolling 7 -day closure v. $21.7 \%$ with no closure), regardless of whether vaccination was also used (Table 4). The attack rate was similar for all closure scenarios, even when a rolling closure was compared to a blanket closure

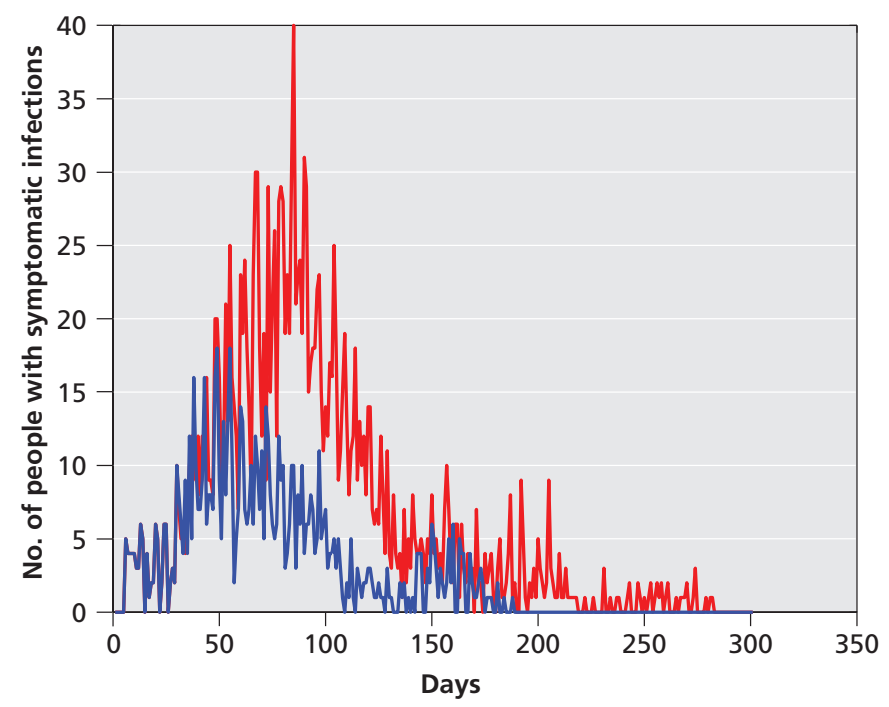

Figure 2: Number of symptomatic infected people versus time in a single simulation, for the baseline scenarios of no mitigation (red) and mitigation by vaccination of $30 \%$ of the population starting at 30 days after onset of the outbreak (blue). (e.g., rolling 14-day closure $1.3 \%$ v. blanket 14-day closure $1.3 \%$ ), because schools and daycares are closed more often under rolling closure scenarios.

Significant reductions in the attack rate were found with vaccination, even without school or daycare closure (e.g., vaccination $4.0 \% \mathrm{v}$. no vaccination $21.7 \%$ ), but delays in vaccine availability compromised the effectiveness of vaccination (Table 4). For example, in the setting of school or daycare closure, vaccinating 60 days after the outbreak began had little impact on the attack rate (e.g., 30\% vaccination after 60 days: $3.2 \%$ v. no vaccination: $3.4 \%$ ). Vaccinating $30 \%$ of the population before the outbreak began was as effective at reducing the attack rate as vaccinating $60 \%$ of the population 30 days after the start of the outbreak (e.g., without school closure: $30 \%$ vaccination before outbreak $3.7 \%$ v. $60 \%$ vaccination 30 days after beginning of outbreak $3.7 \%$ ). Vaccinating $60 \%$ of the population before the outbreak virtually prevented the epidemic (without school closure: attack rate $0.7 \%$ ).

Pre-existing immunity in 5\% of the population resulted in relatively modest reductions in attack rates for all mitigation scenarios (Table 5). However, pre-existing immunity in 15\% of the population resulted in disproportionately large reductions (e.g., without vaccination or school closure: $6.7 \% \mathrm{v}$. $29.4 \%$ at $0 \%$ pre-existing immunity). In this scenario, vaccination 60 days after the start of the outbreak reduced the attack rates from $6.7 \%$ to below $5 \%$ (3.4\% if $30 \%$ of the population has been vaccinated; $2.6 \%$ if $60 \%$ has been vaccinated). Transmission models often exhibit this type of disproportionate, or "nonlinear," response to changes in a parameter.

The disease activity trigger used to initiate interventions had a notable impact on the attack rate, with lower trigger thresholds always having a much larger impact (e.g., $0.8 \%$ if antivirals and school closure are triggered once the first case has been diagnosed; $11.1 \%$ if triggered once $5 \%$ of the population has been diagnosed; Table 6). The presence of antiviral drug resistance did not significantly affect the attack rates (Appendix 1), perhaps because we assumed that drugs would be used only for treatment. A lower transmission probability per contact $\left(R_{0}=1.4\right)$ did not change the relative effectiveness of strategies (Appendix 1).

\section{Interpretation}

The results of our pandemic influenza simulation model suggest that vaccination can have a disproportionately large impact on reducing the attack rate in a "fall wave," although delays can significantly erode its effectiveness. (Because the start of the school year brings increased opportunities for transmission, we assumed "day 0" of the simulation to be early September 2009.) However, if $15 \%$ of the population has pre-existing immunity from transmission in spring and summer 2009, the attack rates may be significantly reduced, even with imperfect mitigation strategies. School closure is projected to be very effective, and lower "trigger" thresholds for school closure may further reduce the attack rate. Even if there is no pre-existing immunity, the pandemic may be halted almost entirely if school closure is triggered at a low 
threshold and is combined with at least some vaccination, or if $60 \%$ of the population is vaccinated before the outbreak begins. These results were consistent across a wide range of assumptions about the epidemiology of pandemic influenza and characteristics of mitigation strategies.

The projected effectiveness of school closure in models and the empirical data in support of school closure vary broadly across studies. ${ }^{7}$ Part of this variability may be because of different study methods, and part may also be because of different mixing patterns in different populations. For example, school closure may be less effective in populations with larger family sizes or extended families. ${ }^{26}$ Closing schools may also be less effective if students spend more time congregating at parties or in playgrounds. However, our model takes this partly into account by reassigning students to spend time in the community if their school is closed (Table 2). We note that there are important social costs of school closures that have not been considered in this analysis. ${ }^{12}$

\section{Limitations and strengths}

Our simulation model has several limitations. One is the small population size, which did not permit larger workplaces to be modelled. Another is that mortality was not included and vaccination was not targeted. As a result, prioritization of vaccine for specific age or risk group could not be addressed. Targeted vaccination of schoolchildren may potentially have strong herd immunity effects. ${ }^{27}$ Future work should assess targeted vaccination of children and a broader range of outcomes, including case fatality rates and economic outcomes. ${ }^{12}$ We assumed that pre-existing immunity came only from pandemic (H1N1) 2009 transmission in the spring and summer of 2009. However, immunity can also come from previous vac-

Table 5: Pandemic influenza attack rate for 3 levels of pre-existing immunity under various vaccination and school closure strategies

\begin{tabular}{|c|c|c|c|}
\hline \multirow[b]{2}{*}{ Variable } & \multicolumn{3}{|c|}{ Overall pre-existing immunity level; attack rate, $* \%$, median (1st, 3rd quartile) } \\
\hline & $0 \%$ & $5 \%$ & $15 \%$ \\
\hline No mitigation & $29.4(29.1,30.1)$ & $21.4(21.3,22.2)$ & $6.7(6.1,7.8)$ \\
\hline \multicolumn{4}{|l|}{ School and daycare closure } \\
\hline Rollingt 7-day & $7.0(5.0,11.3)$ & $4.7(3.0,8.2)$ & $1.9(1.2,3.4)$ \\
\hline Rolling 14-day & $4.9(3.2,9.5)$ & $3.8(2.3,7.4)$ & $1.8(1.1,3.6)$ \\
\hline Blanket‡ 14-day & $4.2(2.6,9.1)$ & $3.3(2.1,7.3)$ & $1.6(1.0,3.6)$ \\
\hline Blanket 300-day & $4.0(2.4,8.6)$ & $3.2(1.9,7.0)$ & $1.7(1.0,3.7)$ \\
\hline \multicolumn{4}{|l|}{ Vaccination, $\%$ of population } \\
\hline $30 \%$, before outbreak & $8.0(7.3,9.2)$ & $3.5(3.1,4.5)$ & $0.7(0.6,3.1)$ \\
\hline $30 \%$, starting 30 days after outbreak begins & $11.8(11.1,12.5)$ & $7.7(6.7,8.4)$ & $1.7(1.5,1.8)$ \\
\hline $30 \%$, starting 60 days after outbreak begins & $19.6(18.8,20.2)$ & $12.5(11.6,13.6)$ & $3.4(2.7,3.7)$ \\
\hline $60 \%$, before outbreak & $1.2(1.1,1.4)$ & $0.8(0.6,0.8)$ & $0.3 \quad(0.2,0.3)$ \\
\hline $60 \%$, starting 30 days after outbreak begins & $5.8(5.3,6.2)$ & $3.9(3.4,4.0)$ & $1.3(1.1,1.3)$ \\
\hline $60 \%$, starting 60 days after outbreak begins & $15.9(15.1,16.9)$ & $9.6(8.7,10.8)$ & $2.6(2.2,2.7)$ \\
\hline
\end{tabular}

*Calculated from all other possible combinations of vaccination, school and daycare closure, antiviral drug use, triggers and drug resistance.

tDiagnosis of an infection in a school or daycare caused the location to be closed.

‡Diagnosis of an infection in a school or daycare caused every school and daycare in its community to be closed.

Table 6: Attack rate under 3 trigger scenarios for school or daycare closure or antiviral treatment, under various combinations of mitigation strategies

Trigger; attack rate, * $\%$, median (1st, 3rd quartile)

\begin{tabular}{lccc}
\cline { 2 - 3 } Strategy & $\begin{array}{c}\text { Once the first fall case has } \\
\text { been diagnosed }\end{array}$ & $\begin{array}{c}\text { Once } 1 \% \text { of the population } \\
\text { has been diagnosed }\end{array}$ & $\begin{array}{c}\text { Once 5\% of the population } \\
\text { has been diagnosed }\end{array}$ \\
\hline $\begin{array}{l}\text { All antiviral treatment, school and } \\
\text { daycare closure, and vaccination } \\
\text { scenarios }\end{array}$ & $0.5(0.3,0.8)$ & $1.9(1.2,3.2)$ & $5.4(2.1,8.9)$ \\
$\begin{array}{l}\text { Antiviral treatment and school } \\
\text { and daycare closure scenarios only }\end{array}$ & $0.8(0.5,1.2)$ & $3.39(1.9,4.4)$ & $11.1(5.6,13.7)$ \\
$\begin{array}{l}\text { Antiviral treatment and } \\
\text { vaccination scenarios only }\end{array}$ & $4.7(1.4,10.7)$ & $5.9(1.8,12.2)$ & $6.6(2.0,14.1)$ \\
\hline
\end{tabular}

*Calculated from all other possible combinations of vaccination, antiviral drug use, school and daycare closure, drug resistance, and pre-existing immunity. 
cines or pandemics. Newly published research shows evidence for pre-existing cross-reactive antibody response to pandemic (H1N1) 2009 ranging from 4\% in people born after 1980 to $34 \%$ in adults born before $1950 .{ }^{28}$ Our baseline assumption of $5 \%$ pre-existing immunity may therefore be conservative. Finally, our model does not take into account the de novo emergence of drug resistance. However, simulation results suggest that drug resistance has a limited effect on attack rates if drugs are used only for treatment (Appendix 1), so this may not be a major limitation.

A strength of this model is its analysis of multiple mitigation strategies, which captures how the effectiveness of one mitigation strategy depends on what other strategies are being used in the population. Another strength is the combinatorial uncertainty analysis, which captured the impact of multiple uncertainties on the effectiveness of mitigation strategies. Such a combinatorial analysis is facilitated by the use of a relatively small population size.

\section{Conclusion}

Timely action is disproportionately effective in reducing the attack rate in an influenza epidemic caused by a newly emerged pandemic flu strain. This finding is particularly important given the early emergence of pandemic (H1N1) 2009 in schools in September 2009. Future research on infectious disease transmission modelling should incorporate formal uncertainty and sensitivity analyses more extensively, particularly in pandemics where uncertainties can be substantial in the early stages.

This article has been peer reviewed.

Competing interests: Beate Sander has held consulting contracts with Hoffmann La-Roche, Switzerland, related to economic evaluations of Tamiflu for treatment and postexposure prophylaxis in epidemics and pandemics. This work involved giving presentations at scientific meetings, for which she received travel assistance and a speaker's fee. David Fisman holds an Ontario Early Researcher Award funded by the Ontario Ministry of Research and Innovation. Matching funds for this grant were provided by Sanofi-Pasteur, which manufactures influenza vaccines, including vaccine for $\mathrm{pH} 1 \mathrm{~N} 1$ (for use outside Canada). None declared for Marija Zivkovic Gojovic, Murray Krahn and Chris Bauch.

Contributors: Marija Zivkovic Gojovic, Beate Sander and Chris Bauch were involved in the conception and design of the study, developing the model, data acquisition and analysis and writing the manuscript. David Fisman was involved in the conception and design of the study, data acquisition and analysis, and drafting the manuscript. Murray Krahn was involved in the conception and design of the study, drafting the manuscript and supervision. The article has been read and approved by all authors. Marija Zivkovic Gojovic had full access to all of the data in the study and takes responsibility for the integrity of the data and the accuracy of the data analysis.

Acknowledgements: The authors thank Brian Schwartz, Monir Taha and Heather Manson for helpful discussions.

Funding: This study was supported by an operating grant from the Canadian Institutes of Health Research, which provided fellowship support for Marija Zivkovic Gojovic and Beate Sander, and by the Ontario Ministry of Research and Innovation.

The funders had no role in the design and conduct of the study; collection, management, analysis and interpretation of the data; or preparation, review or approval of the manuscript. The researchers are independent from the funders.

\section{REFERENCES}

1. World Health Organization. Preparing for the second wave: lessons from current outbreaks. Geneva (Switzerland): The Organization; 2009. Available: www.who.int /csr/disease/swineflu/notes/h1n1_second_wave_20090828/en/index.html (accessed 2009 Sept. 30).

2. Dushoff J, Plotkin J, Levin S, et al. Dynamical resonance can account for seasonality of influenza epidemics. Proc Natl Acad Sci U S A 2004;101:16915-6.

3. Flahault A, Vergu E, Boelle P. Potential for a global dynamic of influenza A (H1N1). BMC Infect Dis 2009;9:129.

4. Fraser C, Donnelly C, Cauchemez S, et al. Pandemic potential of a strain of influenza A (H1N1): early findings. Science 2009;324:1557-61.

5. Hebert $\mathrm{P}$, MacDonald $\mathrm{N}$. The H1N1 vaccine race: Can we beat the pandemic? CMAJ 2009. DOI:10.1503/cmaj.091560.

6. Ferguson NM, Cummings DA, Cauchemez S, et al. Strategies for containing an emerging influenza pandemic in Southeast Asia. Nature 2005;437:209-14.

7. Cauchemez S, Ferguson N, Wachtel C, et al. Closure of schools during an influenza pandeic. Lancet Infect Dis 2009;9:473-81.

8. Medlock J, Galvani A. Optimizing influenza vaccine distribution. Science 2009; 325:1705-8.

9. Moghadas S, Bowman C, Rost G, et al. Population-wide emergence of antiviral resistance during pandemic influenza. PLoS One 2008;3:e1839.

10. Longini IM, Halloran ME, Nizam A, et al. Containing pandemic influenza with antiviral agents. Am J Epidemiol 2004;159:623-33.

11. Glasser J. Evaluation of targeted influenza vaccination strategies via population modeling [presentation]. Atlanta (GA): National Centre for Immunization and Respiratory Diseases, CDC; 2007. Available: http://dimacs.rutgers.edu/Workshops /AfricaDiseases/slides/glasser.pdf. (accessed 2009 Sept. 30).

12. Sander B, Nizam A, Garrison Jr. LP, et al. Economic evaluation of influenza pandemic mitigation strategies in the United States using a stochastic microsimulation transmission model. Value Health 2008; 12:226-33.

13. Blower SM, Dowlatabadi H. Sensitivity and uncertainty analysis of complex models of disease transmission: HIV as an example. Int Stat Rev 1994;62:229-43.

14. Census of Canada, 2006. Ottawa (ON): Statistics Canada; 2006. Available: www12.statcan.gc.ca/census-recensement/index-eng.cfm (accessed 2009 Sept. 30).

15. Enrolment by grade. London (ON): Thames Valley District School Board; 2008. Available: www.tvdsb.ca/documents.cfm?id=191 (accessed 2009 Oct. 6).

16. Boëlle PY, Bernillon P, Desenclos JC. A preliminary estimation of the reproduction ratio for new influenza A (H1N1) from the outbreak in Mexico, March-April 2009. Euro Surveill 2009; 14: pii:19205.

17. Treanor JJ, Hayden FG, Vrooman PS, et al. Efficacy and safety of the oral neuraminidase inhibitor oseltamivir in treating acute influenza: a randomized controlled trial. US Oral Neuraminidase Study Group. JAMA 2000;283:1016-24.

18. Whitley RJ, Hayden FG, Reisinger KS, et al. Oral oseltamivir treatment of influenza in children. Pediatr Infect Dis J 2001;20:127-33.

19. Vu T, Farish S, Jenkins M, et al. A meta-analysis of effectiveness of influenza vaccine in persons aged 65 years and over living in the community. Vaccine 2002;20: 1831-6.

20. Mossong J, Hens N, Jit M, et al. Social contacts and mixing patterns relevant to the spread of infectious diseases. PLoS Med 2008;5:e74.

21. Coburn BJ, Wagner BG, Blower S. Modeling influenza epidemics and pandemics: insights into the future of swine flu (H1N1). BMC Med 2009;7:30.

22. Pandemic Influenza Outbreak Research Modelling Team (PanInfORM). Modelling an influenza pandemic: a guide for the perplexed. CMAJ 2009;181:171-3.

23. Diekmann O, Heesterbeek J, Metz J. On the definition and the computation of the basic reproduction ratio $\mathrm{R}_{0}$ in models for infectious diseases in heterogeneous populations. J Math Biol 1990;28:365-82.

24. Pourbohloul B, Ahued A, Davoudi B, et al. Initial human transmission dynamics of the pandemic (H1N1) 2009 virus in North America. Influenza Other Respi Viruses 2009;3:215-22.

25. Ontario Health Plan for an Influenza Pandemic. Toronto (ON): Ontario Public Service Employees Union; 2008. Available: www.opseu.org/hands/influenzaplan.htm (accessed 2009 Sept. 30)

26. Reichert TA, Sugaya N, Fedson DS, et al. The Japanese experience with vaccinating schoolchildren against influenza. N Engl J Med 2001;344:889-96.

27. Glezen WP. Herd protection against influenza. J Clin Virol 2006;37:237-43.

28. Hancock K, Veguilla V, Xiuhua L, et al. Cross-reactive antibody responses to the 2009 pandemic H1N1 influenza virus. N Engl J Med 2009. DOI 10.1056/NEJMoa0906453.

Correspondence to: Dr. Marija Zivkovic Gojovic, Toronto Health Economics and Technology Assessment Collaborative, University of Toronto, 144 College St., Toronto ON M5S 3M2;

fax 416 946-3719; mgojovic@uhnres.utoronto.ca 